\title{
Environmental change and adaptation in degraded agro-ecosystems: the case of highland Madagascar
}

\author{
Jon Unruh*, Bill McConnell** and Joe Rodman $\dagger$ \\ *Department of Geography, McGill University, Montreal, QC, Canada H3A 2K6 \\ Email: jon.unruh@mcgill.ca \\ **Department of Fisheries and Wildlife, 13 Natural Resources Building, Michigan State \\ University, East \\ Lansing, MI 48824-1222, USA \\ $†$ Department of Geography, Indiana University-Bloomington, Bloomington, IN 47405, \\ USA
}

\begin{abstract}
While the view that the poorer agricultural populations in developing countries will be at the forefront of negative consequences due to environmental change is widely accepted, this perspective must become considerably more nuanced in order to recognize and take advantage of emerging opportunities for realistic adaptation. This paper presents a case from Madagascar which suggests that adaptation opportunities involve more than looking for alternatives to what are presently perceived to be negative socio-ecologic processes. In Madagascar the severe erosion occurring on the deforested central plateau actually appear to create, over time, opportunities for increased food security and environmental management compared to un-eroded portions of the same landscape. The paper proposes that while concern and action is needed to attend to the problems that the poor of the developing world will face due to impacts from environmental change, the repercussions of such change on agricultural systems also need to be looked at in ways that involve recognizing the local and aggregate potential opportunities that they may present in certain systems, in order to realize the prospects for adaptation.
\end{abstract}

Keywords: Environmental change, adaptation, land degradation, Madagascar, erosion

\section{Introduction}

As the scientific, policy and applied efforts focused on global environmental change and in particular climate change move forward, increasing attention is focused on the ability of societies to adapt. Generally it is thought that among the most vulnerable to such changes will be the rural poor who occupy degraded and marginal environments in the developing world. This is because these populations depend most directly on natural resources for livelihoods, but at the same time do not possess options for planning and management which are open to others occupying more optimal agricultural environments (e.g., Dilley and Boudreau, 2001; Kelly and Adger, 2000; Downing, 2002; Eriksen et al., 2005; Beg et al., 2002; Reilly and Schimmelpfenning, 1999; Eakin and Luers, 2006; Mendelsohn and Dinar, 1999). Africa is of particular concern in this regard (e.g., 
Magadza, 2000; Smith and Lenhart, 1996; Mohamed et al., 2002; Toulmin, et al., 2005; Black, 2006). However such a broad approach to peoples and areas as 'most vulnerable', while enjoying a certain logic, lacks acknowledgement of the many directions that land degradation takes, and how this intersects with local innovation and unexpected forms of adaptation that may significantly decrease livelihood vulnerability. This paper argues that the impacts of environmental change on agricultural systems in the developing world need to be looked at in ways which include recognizing the potential opportunities that such impacts may themselves present in certain systems, in order to more comprehensively understand the possibilities for adaptation.

This article makes a preliminary examination of a case from Madagascar, which suggests that adaptation opportunities can include variations which actually take advantage of what are presently perceived to be negative socio-ecologic processes associated with environmental change. This may particularly be the case where such processes have already moved certain agricultural systems into serious land degradation and food insecurity. While additional data gathering is needed, we present preliminary findings here based on qualitative observations and the literature, and comment on possible lessons learned.

\section{The Malagasy Highlands}

Madagascar's highlands cover approximately one-fifth of the island and the physiography varies between rolling hills, plains, incised valleys, rolling and volcanic cones and massifs (Kull, 1998). The area is occupied by the Merina and Betsileo ethnic groups and is one of the most populated regions of the country, with more than six million people, and a density over 200 people per $\mathrm{km} 2$ (Kull, 1998). The indices of poverty in the highlands are among the highest in the country (Mistiaen, 2002). Historic vegetation comprised mosaics of forest in riparian areas, woodlands, grasslands and heath (Kull, 1998). With the onset of human occupation in the $13^{\text {th }}$ century there was increased burning for agriculture, hunting, and pasture, which resulted in significant grassland expansion (Kull, 1998; Burney, 1997; Dewar and Wright, 1993).

\section{Land Degradation}

Deforested and eroded landscapes are important outcomes of environmental change, and contribute to compromised agricultural systems, food security, and livelihoods (e.g., Kakembo and Rowntree, 2002; Clay and Lewis, 1990; Jarosz, 1993; Poesen et al., 2003; Mushala, 1997; Lal, 2001). Deforestation and soil erosion in Madagascar has received significant attention, with numerous studies describing severely degraded highland ecosystems and agriculture (e.g., Gade, 1996; Kull, 1998; Jarosz, 1993; Tricart, 1953; Sussman et al., 1994). The Malagasy central plateau (Figure 1) has been the site of land degradation since the onset of human occupation of the island, with deforestation resulting in a largely treeless region, pocketed by extreme forms of erosion which are tied to human use of the landscape (e.g., Wells and Andriamihaja, 1993; Tricart, 1953; Wells et al., 1991). Erosion in highland Madagascar frequently manifests itself in very large 
numbers of deep cuts and collapsed hillsides (lavaka), mudflows, slumping and mass flows. The lavaka and associated processes are particularly pervasive (Figure 2). These form an initial cut or gap in a hillside, and then widen and lengthen over time to become much longer and broader landscape features (Wells et al., 1987). Figures 3 - 5 illustrate such a progression.

A review of the prototypical erosional process in the central highlands posits a range of anthropogenic and natural causes over time (Wells and et al, 1987, 1993 and the references cited therein; Harvey et al., 1985). The human factors include historic creation of fortifications on hilltops, the formation of tracks and trails by humans and livestock, overgrazing, deforestation, the construction of canals and rice paddies, the placement of agricultural fields on denuded hills, use of fire to promote pasture prior to the onset of the rainy season, and the deliberate initiation of lavaka in order to purposefully alluviate valley floors so as to create large, flattened areas for rice cultivation (Gade, 1996; Kull, 1998; Jolly, 1987; Wells and Andriamihaja, 1993; Paulian, 1984; Gallegos, 1997). Natural processes include an interaction of progressive drying in the late Holocene (MacPhee, 1986), rainfall and runoff together with bare surfaces, large-scale mass movements of soil, small-scale earth falls, soil slips, the presence of subsurface water and localized groundwater outflow (Wells and Andriamihaja, 1993). Climate change due to human activities is also thought to be a significant factor, with Wells and Andriamihaja (1993, 31 ) noting that " $[t]$ emperature, and /or rainfall shifts, changes in storminess, timing of rains, changes in seasonal wetting and drying cycles, and the like could easily affect vegetation and erosion in many ways." The interaction of human and natural influences has resulted in an enormous increase in the occurrence of erosional features on the highland landscape over time, as population increase, problematic land tenure, a variety of land use practices and biophysical processes operate together (Gallegos, 1997; Wells and Andriamihaja, 1993).

\section{From Erosion to Agriculture}

While the biophysical formation of lavaka has been well elaborated by Wells et al. (1991), Wells and Andriamihaja (1993), and Gade (1996); what has not been examined is how local inhabitants are able to take advantage of the widespread presence of these erosional features once they have become pervasive across highland landscapes, to further their development so as to improve food security and livelihood resilience. Of interest in an adaptation context, is this development over time. Wells et al. (1991) outline the various stages of lavaka maturation, from an initial sharp incision, to much larger more worn features. As the walls of lavaka erode, retreat, and become more rounded, they grow much wider and longer. They can expand to reach the valley floor, and can eventually end up as significant side-valleys (Wells et al., 1991). The more mature lavaka are then the focus of intensive agricultural activity by local inhabitants (Figure $5 \mathrm{a}-\mathrm{c}$ ). This occurs in-part because rains, runoff and continued erosion deposit soil (and associated nutrients) into concentrated locations within these cuts and at the outflows, providing favorable localized conditions in which to plant annual and perennial crops, 
pursue terracing activities, and control how further erosion and deposition occurs. With continued modification by local inhabitants, the rugged nature of the cut changes over time, to become an intensively managed tree-crop association.

Figures 3 - 5 illustrate the progression of lavaka for the purpose of agricultural adaptation to the opportunities such features provide, or can be managed to provide. Figure $3 \mathrm{a}-\mathrm{d}$ show young lavaka as raw cuts in hillsides. Figure $4 \mathrm{a}, \mathrm{b}$, and d show a series of more mature lavaka with some initial agricultural management including cultivated fields and agroforestry on the outflow at the foot of the lavaka. Figure $4 \mathrm{c}$ is a photograph of natural tree colonization inside of a lavaka. Figure 5a - c illustrate developed crop agriculture in still more mature lavaka which have grown to become small side valleys. Evident in Figure 5 is the intensive management of agriculture, particularly with regard to terracing. Figure $6 \mathrm{a}$ and $\mathrm{b}$ illustrate the prevalence of lavaka on the landscape from air photos, and the overall presence of vegetation (especially woody vegetation) which reside primarily within or associated with these erosional features. For all photos note that there is almost no agriculture and very little tree presence outside of the lavaka. This is particularly evident when aerial views are examined (Figure 6a, b).

The length of time it takes for lavaka to become productive is an important, albeit complicated question. While this study did not examine this specifically, and it goes unreported in the literature, a number of variables are important in the time required for a lavaka to attain some form of productivity. Presumably if a farmer were to initiate the creation of a lavaka this would perhaps indicate the prospect of at least a medium-term return in terms of productivity in some form. In addition, certain parts of lavaka will be productive earlier than others. Outflows at the foot of lavaka for example will likely be productive more quickly, especially for annual crop production, than the more interior components which can still be undergoing relatively early stages of erosion at the same time. Certain locations within lavaka, such as places of significant soil and water deposition may be selected earlier for planting economic trees, while other parts of a lavaka will be developed at a later time. As well the level of attention given to the development of lavaka by farmers will be variable. The amount of time in a given month or year that a farmer is able to devote to the productive development of a lavaka will have a significant influence on the time needed for a lavaka to attain productivity. As well any given farmer may have a few lavaka that are intensively invested in, developed and used, while other lavaka the same farmer owns receives less attention and so will take longer to develop into a particular stage of productivity. Tenure security will also likely play a role. The link between tenure security and investment by small scale agriculturalists is well established; such that if farmers believe they do not have security of tenure, then they will be less likely to invest (particularly with regard to investments such as terraces and tree crops). Then there is the definition of 'productivity' from the perspective of the farmer. Utility and value from lavaka can be realized from a variety of different kinds of useful lavaka. Even lavaka with only naturally occurring trees can still be 'productive' and useful for the minor forest products they produce. At the other end of 
the continuum of course are very intensively developed lavaka with stands of economic trees, terraces, and residences.

The Madagascar case provides an example where severe land degradation-one of the repercussions of environmental change--may provide for unexpected opportunities for adaptation. This occurs as landscapes become 'loaded' with numerous features of degradation (Figures $6 \mathrm{a}, 6 \mathrm{~b}$ ) that are more pronounced (erosion) than the initial form of degradation (deforestation). In this case the more acute form of degradation is what is managed, and what presents the opportunity for adaptation. The frequency of agriculturally occupied erosional features in the highlands, together with the frequency of those that contain primarily woody biomass from which minor forest products are collected, in aggregate, present the possibility for greater livelihood resilience and food security at the local to landscape scale, than if such features did not occur on the denuded highlands. ${ }^{1}$

\section{Lessons Learned}

The prospects for 'lessons learned' for this type of adaptation exist at three levels, 1) local, customary approaches for management of individual lavaka or sets of lavaka and their immediate surroundings, 2) the national development approaches for planning and management of agricultural and conservation projects, and 3) the more global treatment of options for adaptation to environmental change and the prospects for mitigation of such change.

At the local level, communities in highland Madagascar are certainly aware of the opportunities that lavaka present, hence their interest in encouraging their formation, and their ability to develop them. For such communities, adaptation involves both considering where on the landscape initiating the hillside collapses that subsequently turn in to useful lavaka might be employed, and where and how to utilize naturally occurring lavaka. The existence of intensive agriculture within mature lavaka (Figure 5a-c), attests to the existence of fairly well developed strategies on the part of local households and communities. Purposeful management strategies at this level appear to focus on localized needs for agricultural production within cultivated lavaka, and fuelwood and other minor forest products available from nearby lavaka containing stands of woody vegetation growth (Figure 4c). Thus in agricultural lavaka, management focuses on planting annual and perennial crops in and along crevices (especially in younger lavaka, Figure a, b, and d), and the construction of terraces and their agricultural management in the more mature lavaka (Figure 5c). In both younger and older lavaka, agricultural management of

${ }_{1}$ Use of erosional processes to expand food security opportunities are also known elsewhere. In Sonora, Mexico, erosional deposition in desert landscapes are controlled with the construction of fencerows to slow and spread out flow from annual rains, depositing sediment over an area larger than what would have occurred naturally. Such areas are then planted, and over time these expand into significant cultivated areas (Nabhan and Sheridan, 1977). 
outflows at the bottom for both annual and perennial crops is evident (e.g. Figure 4a, b, d).

At the national level the lessons learned that would facilitate recognition and use of local adaptations that may develop in unexpected or counterintuitive directions, would need to begin with a departure from the conservationist paradigm which holds there to be a set desired directional response to land degradation - essentially reversing degradation. As this case shows, forms of degradation themselves (e.g. erosion in this example) can, under certain circumstances, be useful to forms of adaptation. In this context the specific lesson would be the need to look beyond what appear to be detrimental components of smallholder responses to environmental change (erosion and hillside collapse in this case) to a more comprehensive planning process that allows for such components to be viewed has having possibilities other than increased degradation and the resulting increase in population vulnerability only. And while degradation processes, features, and local responses will certainly not always contain the prospect of positive adaptation, when they do, their potential can be missed if there is not the strategic awareness of this possibility.

In this regard top down planning and management approaches are problematic in that they can assume there are no valuable counterintuitive environmental management approaches that could emerge from the local level, and as a result these can remain unrealized. For national level development planning it can be productive to first examine what local populations are already doing and the possible directions it may take them. One of the more general themes that this case illustrates about the process of adaptation, is that for people who continue to live in degraded and very degraded environments, an important question is, what are they currently doing to, a) continue to be able to live in such an environment, and b) to try to move agricultural and resource exploitation possibilities in new directions.

At the international policy level, two potential lessons are important; the prospect for applying the approach elsewhere, and the aggregate, large scale implications and repercussions of population-wide forms of adaptation or conservation, such as forms of carbon sequestration in woody biomass, and improving food security. With regard to the former, Wells et al (1991) note that Malagasy lavaka are similar to features described in Brazil and New Zealand, such that a very similar approach may be applicable in other countries. At the aggregate scale, policy priorities can suffer from a variety of international to local top-down problems, including, 1) favoring (and hence supporting) what is perceived to benefit aggregate (e.g. international) scale goals, 2) a nonappreciation of locally derived approaches to adaptation that have local benefits, and 3 ) the design and implementation of on-the-ground projects which presume that a set of benefits will accrue to local populations, when in reality their adoption can be difficult.

The problematic nature of 'benefits' with regard to internationally recognized adaptation directions and projects has received little attention in the adaptation literature but is 
relevant to the Madagascar case. The primary problem is that predicted benefits to communities as a result of top-down adaptation approaches are not compared to benefits already in existence at the local level which would be changed or lost with the implementation of such adaptation schemes. How the two sets of benefits compare in quantity, quality, type, functionality, and in particular who within communities will gain and lose with a change from one set to the other, is fundamental to the realization of benefits associated with adapting to new situations and hence the adoption of new approaches. Unfortunately the literature regarding benefits associated with adaptation does not engage such a comparison. Instead what is described are generalized ideas of 'benefits' for local communities, along with the assumption that such benefits will entice adoption of changed practices (e.g. May et al. 2003; Jindal et al 2008; Brown et al. 2001; Pagiola et al. 2002; Toulmin et al. 2005; Smith 2002; Bloomfield and Pearson 2000; Klooster and Masera 2000; Saunders et al. 2002).

At the final plenary of a recent conference on Food Security and Environmental Change (GECAFSs, 2008), a number of points were highlighted as primary policy-relevant conference outcomes. Among these, four are strongly supported by the Madagascar case presented here, 1) that indigenous knowledge and 'high science' should come together to gain insight into the prospects for adaptation; 2) the importance of communities' role in innovative approaches to adaptation, and in integrating these into broader adaptive systems, as opposed to considering the broader food system as the first priority and then working down to the community level; 3) the need to look at what works where and why, and the value of forming typologies of what works in specific localities and how to aggregate up from these experiences, and; 4) the need to guard against dictating forms of adaptation from the top down (GECFAS, 2008).

\section{Conclusion}

This very preliminary consideration of the potential utility of lavaka, does not assess the quantity of food derived or the number of people involved. Instead the intent here is to provide an initial awareness of the potential adaptive response. While more detailed description and analysis is needed, what is already clear, particularly given the intensive agricultural use of lavaka (Figure 5), is that as policies and development initiatives increasingly prioritize adaptation to environmental change, they need to consider becoming more nuanced and innovative (including considering the counter-intuitive) with regard to approaches to agricultural and natural resource planning, management, and conservation, in order to support the local derivation of forms of adaptation.

Presently our understanding of the operative mechanisms and the nature of local capacity regarding different types of adaptation among the poor occupying degraded or problematic landscapes of the developing world is weak. What this case illustrates about the process of adaptation, is that such capacity is not defined and does not operate in only one way (i.e. the ability to engage in conservation of a current or earlier set of resources). 
Indeed a couple of authors have begun to examine considerable variation in adaptive responses (Scherr, 2000; Mortimore and Adams, 2001; Sendzimir and Flacher, 2007). We do not have sufficient knowledge of the many ways that adaptation could work or could emerge.

While the reality that the poorer agricultural populations in developing countries will be at the forefront of negative consequences due to environmental change and particularly climate change is widely accepted, this perspective must become considerably more elaborated in order to recognize and take advantage of unexpected opportunities for adaptation. As Madagascar illustrates, some forms of degradation can themselves become opportunities for adaptation. The notion that 'the poor are most vulnerable', while perhaps useful in an aggregate sense, begins to lose utility as research on adaptation progresses, and local adaptations emerge on their own with very different operative understandings with regard to the constraints and opportunities which result from environmental change.

\section{References}

Bass, S., Budois, O., Costa, P., Pinard, M., Tipper, R., Wilson, C. 2000. Rural livelihoods and carbon management. IIED Natural Resource Issues Paper No 1 International Institute for Environment and Development London

Beg, N., Morlot, J., Davidson. O., Afrane-Okesse, Y., Tyani, L., Denton, F., Sokona, Y., Thomas, J., La Rovere, E., Parikh, J., Parikh, K., Rahman, A., 2002. Linkages between climate change and sustainable development Climate Policy 2, 129-144.

Black, R., 2006, Africa focus for climate summit BBC News Nov 6,

Bloomfield, J., and Pearson, H. 2000. Land use, land-use change, forestry, and agricultural activities in the clean development mechanism estimates of greenhouse gas offset potential. Mitigation and Adaptation Strategies for Global Change 5 9-24.

Brown S, Swingland I, Hanbury-Tension R, Prance G, Myers N. 2001. Carbon sinks for abating climate change can they work? Center for Environment and Society, University of Essex

Burney, D., 1997, Theories and facts regarding Holocene environmental change before and after human colonization in Patterson B and Goodnman M eds Natural and humanInduced change in Madagascar. Washington DC: Smithsonian Press 75-89. 
Clay, D., and Lewis, L., 1990. Land-use soil loss and sustainable agriculture in Rwanda. Human Ecology, 18, 147-161.

Dewar, R., and Wright, H., 1993. The culture history of Madagascar. Journal of World Prehistory, 7, 417-466.

Dilley, M., and Boudreau, T.E., 2001. Coming to terms with vulnerability A critique of the food security definition. Food Policy, 26, 229-247.

Downing, T., 2002. Linking sustainable livelihoods and global climate change in vulnerable food systems. die Erde, 133, 363-378.

Eakin, H., and Luers, A,L., 2006. Assessing the vulnerability of socio-environmental systems. Annual Review of Environment and Resources, 31, 365-394.

Eriksen, S.H., Brown, K., and Kelly, P.M., 2005. The dynamics of vulnerability locating coping strategies in Kenya and Tanzania. The Geographical Journal, 171, 287-305.

Gade, D., 1996, Deforestation and its effects in highland Madagascar. Mountain Research and Development, 16, 101-116.

Gallegos, C., 1997. Madagascar unrealized potential in natural resources. Journal of Forestry, 95, 10-15.

Global Environmental Change and Food Systems (GECAFS), 2008. Synthesis ideas / main conference points, GECAFS Scientific Advisory Committee. Conference on Food Security and Environmental Change: Linking Science, Development, and Policy for Adaptation. April 2-4, University of Oxford, UK

Harvey, M., Watson, C., and Schumm, S., 1985, Gully erosion. US Department of the Interior Bureau of Land Management Technical Note, 336.

Jarosz, L., 1993. Defining and explaining tropical deforestation - shifting cultivation and population-growth in colonial Madagascar (1896-1940). Economic Geography, 69 366-397.

Jindal, R., B. Swallow, and J. Kerr. 2008. Forestry-based carbon sequestration projects in Africa: Potential benefits and challenges. Natural Resources Forum 32:116-130.

Jolly, A., 1987. Madagascar - a world apart. National Geographic, 171 148-183. 
Kakembo, V., and Rowntree, K., 2002. The relationship between land use and soil erosion in the communal lands near Peddie town Eastern Cape South Africa. Land Degradation and Development, 14 (1), 39-49.

Kelly, P., and Adger, W., 2000. Theory and practice in assessing vulnerability to climate change and facilitating adaptation. Climatic Change, 47, 325-352.

Klooster, D., and Masera, O. 2000. Community forest management in Mexico making carbon sequestration a by-product of sustainable rural development. Global Environmental Change 10 259-272

Kull ,C., 1998. Leimavo revisited agrarian land use change in the highlands of Madagascar. Professional Geographer, 50, 163-176.

Lal, R., 2001. Soil degradation by erosion. Land Degradation and Development, 12, 519-539.

MacPhee, R., 1986. Environment extinction and Holocene vertebrate localities in southern Madagascar. National Geographic Research, 2, 441-455.

Magadza, C., 2000. Climatic change impacts and human settlements in Africa prospects for adaptation. Environmental Monitoring and Assessment, 61, 193-205.

May, P., E. Boyd, M. Chang, and F. Viega. 2003. Local sustainable development effects of forest carbon projects in Brazil and Bolivia. Paper presented at the International Conference on Rural Livelihoods Forests and Biodiversity 19-23 May 2003 Bonn Germany.

Mendelsohn. R., and Dinar, A., 1999. Climate change agriculture and developing countries does adaptation matter? World Bank Research Observer, 14 277-292.

Mistiaen. 2002. Putting welfare on the map in Madagascar. World Bank Washington DC.

Mohamed, B., Duivenbooden, N., and Abdoussallam, S., 2002. Impact of climate change on agricultural production in the Sahel. Climatic Change, 54, 327-358.

Mushala, H., 1997, Soil erosion and indigenous land management some socio-economic considerations. Soil Technology, 11, 301-310.

Nabhan, B.G., and Sheridan, T.E., 1977, Living fencerows of the Rio San Miguel Sonora Mexico traditional technology for floodplain management, Human Ecology, 5, 97-111.

Pagiola S, Bishop J, Landell-Mills eds. 2002. Selling forest environmental services 
market based mechanisms for conservation and development Earthscan Publications Ltd, London

Paulian, R., 1984, Madagascar - a continent between Africa and Asia. In: A. Jolly, P. Oberle, and R. Albignac eds Key environments - Madagascar. Oxford: Pergamon 1-26.

Poesen, J., Nachtergaele, J., Verstraeten, G., and Valentin, C., 2003, Gully erosion and environmental change importance and research needs. CATENA, 50, 91-133.

Reilly, J., and Schimmelpfenning, D., 1999. Agricultural impact assessment vulnerability and the scope for adaptation. Climatic Change, 43 745-788.

Saunders, L., Hanbury-Tenison, R., Swingland, I. 2002. Social capital from carbon property creating equity for indigenous people. Philisophical Transactions of the Royal Society London 360 1763-1775.

Smith, J., and Lenhart, S., 1996, Climate change adaptation policy options. Climate Research, 6, 193-201.

Smith, J. 2002. Afforestation and reforestation in the clean development mechanism of the Kyoto Protocol implications for forests and forest people. International Journal of Global Environmental Issues, 2 322-343.

Sussman, R., Green, G., and Sussman, L., 1994. Satellite imagery human ecology anthropology and deforestation in Madagascar. Human Ecology, 22, 333-354.

Toulmin, C., Huq, S., and Rockstrom, J., 2005. Africa and Climate Change. London: International Institute for Environment and Development Sustainable Development.

Tricart, J., 1953. Erosion naturelle et erosion anthropogene a Madagascar. Revue de Geomorphologie Dynamique, 4, 225-230.

Unruh, J. 2006. Land tenure and the evidence landscape in developing countries. Annals of the Association of American Geographers 96 754-772

Wells, N., Andriamihaja, B., and Rakotovolona, H., 1991 Patterns of development of Lavaka Madagascar's unusual gullies. Earth Surface Processes and Landforms, 16, 189-206.

Wells, N., and Andriamihaja, B., 1993. The initiation and growth of gullies in Madagascar are humans to blame? Geomorphology, 8, 1046. 
Wells, N., Andriamihaja, B., and Rakotovololoona, H., 1987, Lavaka

explained .Geotimes, 32, 3.

\section{Figure Captions}

Figure 1. The central highlands of Madagascar. Source: Simmon 2004.

Figure 2, Land degradation on Madagascar's central highlands. Photo: WildMadagascar.org

Figure 3a. Fresh lavaka cut, eroded into hillside. Photo: Team lavaka Image Collection, R Cox.

Figure 3b. Relatively new lavaka, with manioc field on outflow. Photo: Team Lavaka Image Collection, R. Cox.

Figure 3c. Newly forming lavaka. Photo: J. Unruh.

Figure 3d. Recently burned, older lavaka. Photo: J. Unruh.

Figure 4a. Cultivation in outfall area of vegetated, lightly active lavaka. Photo: Team Lavaka Image Collection, Jungers $\mathrm{M}$.

Figure $4 \mathrm{~b}$. Bananas and fields in outfall area of largely inactive, vegetated lavaka. Photo: Team Lavaka Image Collection, R Cox.

Figure 4c. Trees colonising active lavaka. Photo: Team Lavaka Image Collection, R. Cox.

Figure 4d. Agriculturally occupied lavaka outflow. Photo: Team Lavaka Image Collection, M. Jungers.

Figure 5a. Mature lavaka as a side valley with intensive agriculture. Photo: J. Unruh.

Figure 5b. Mature lavaka with crops and trees. Photo: J. Unruh.

Figure 5c. Mature lavaka with terracing and homestead buildings (lower center). Photo: J. Unruh.

Figure 6a. Air photo of numerous lavaka. Photo: J. Unruh.

Figure 6b. Lavaka colonized by tree regrowth. Photo: J. Unruh. 


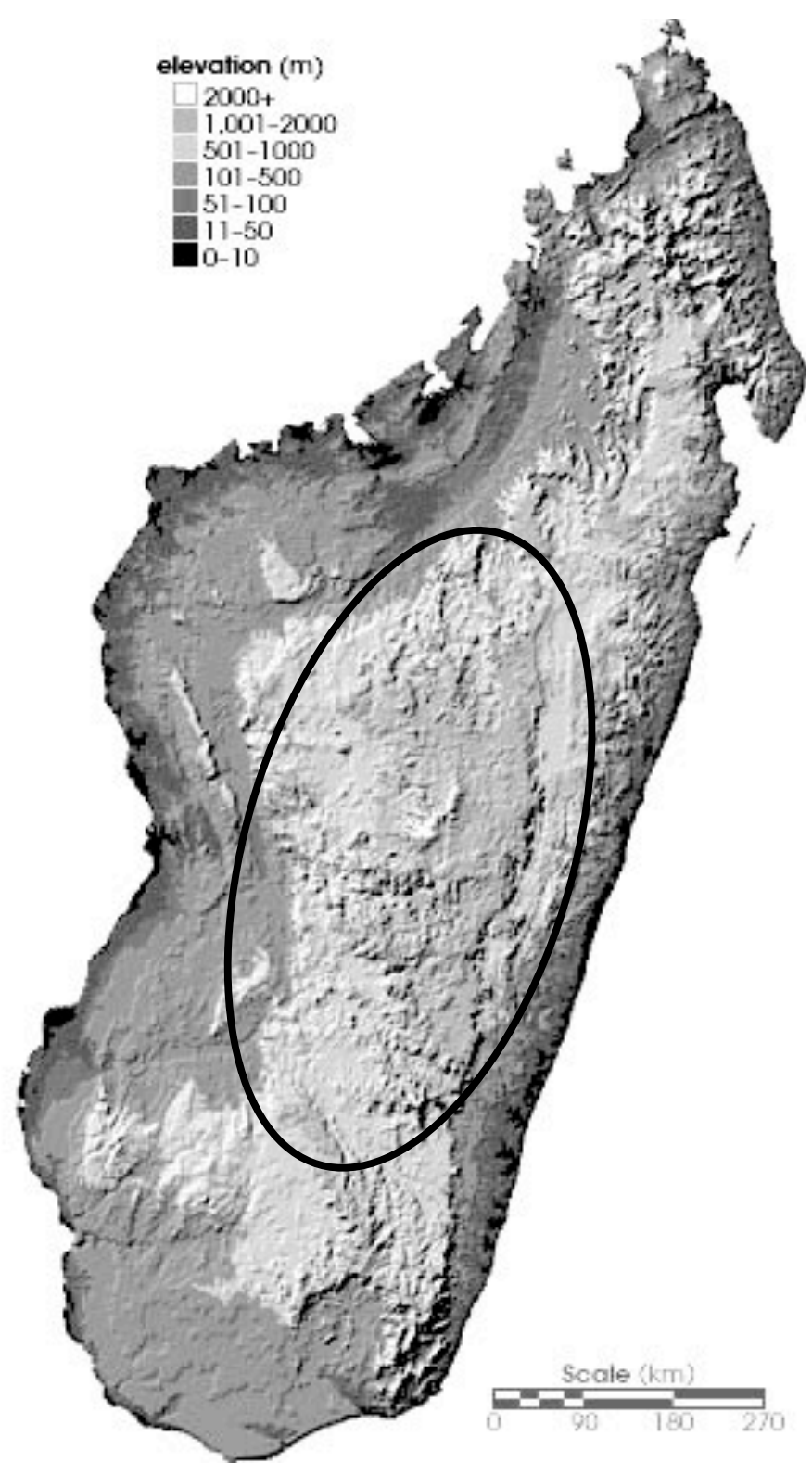

Figure 1. The central highlands of Madagascar. Source: Simmon 2004. 


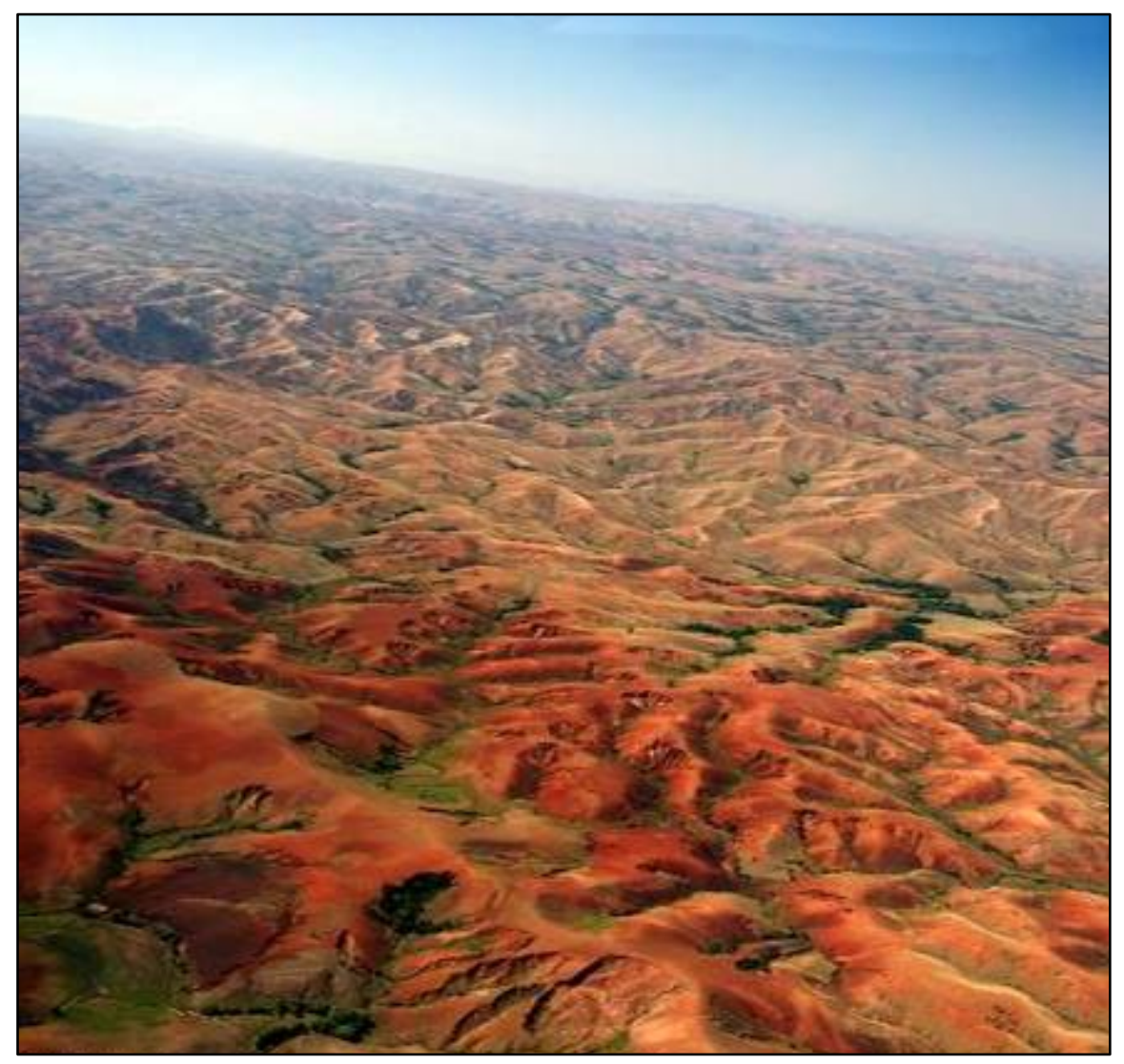

Figure 2, Land degradation on Madagascar's central highlands. Photo: WildMadagascar.org 
Figure 3 a - d

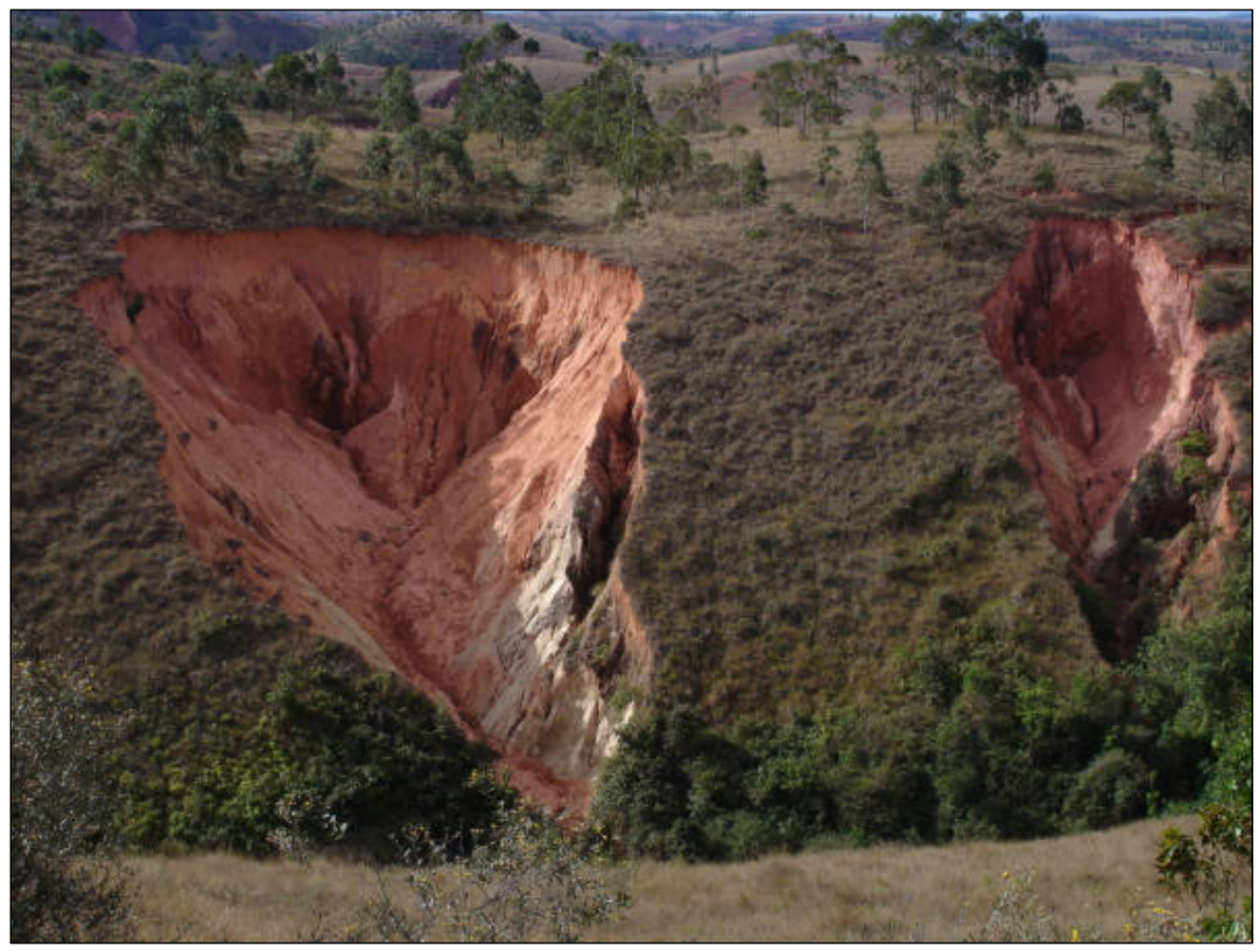

Figure 3a. Fresh lavaka cut, eroded into hillside. Photo: Team lavaka Image Collection, R Cox. 


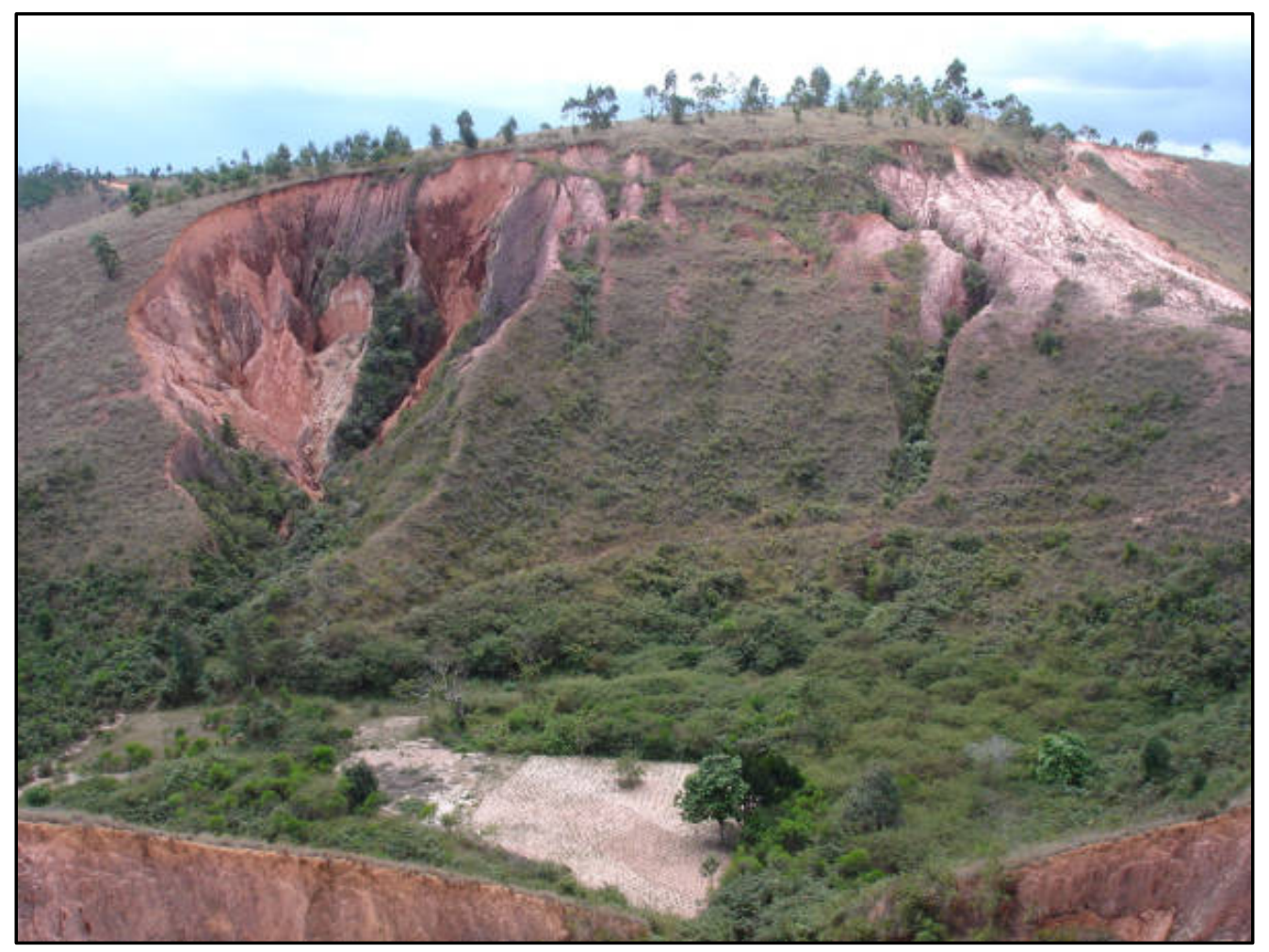

Figure 3 b. Relatively new lavaka, with manioc field on outflow. Photo: Team Lavaka Image Collection, R. Cox.

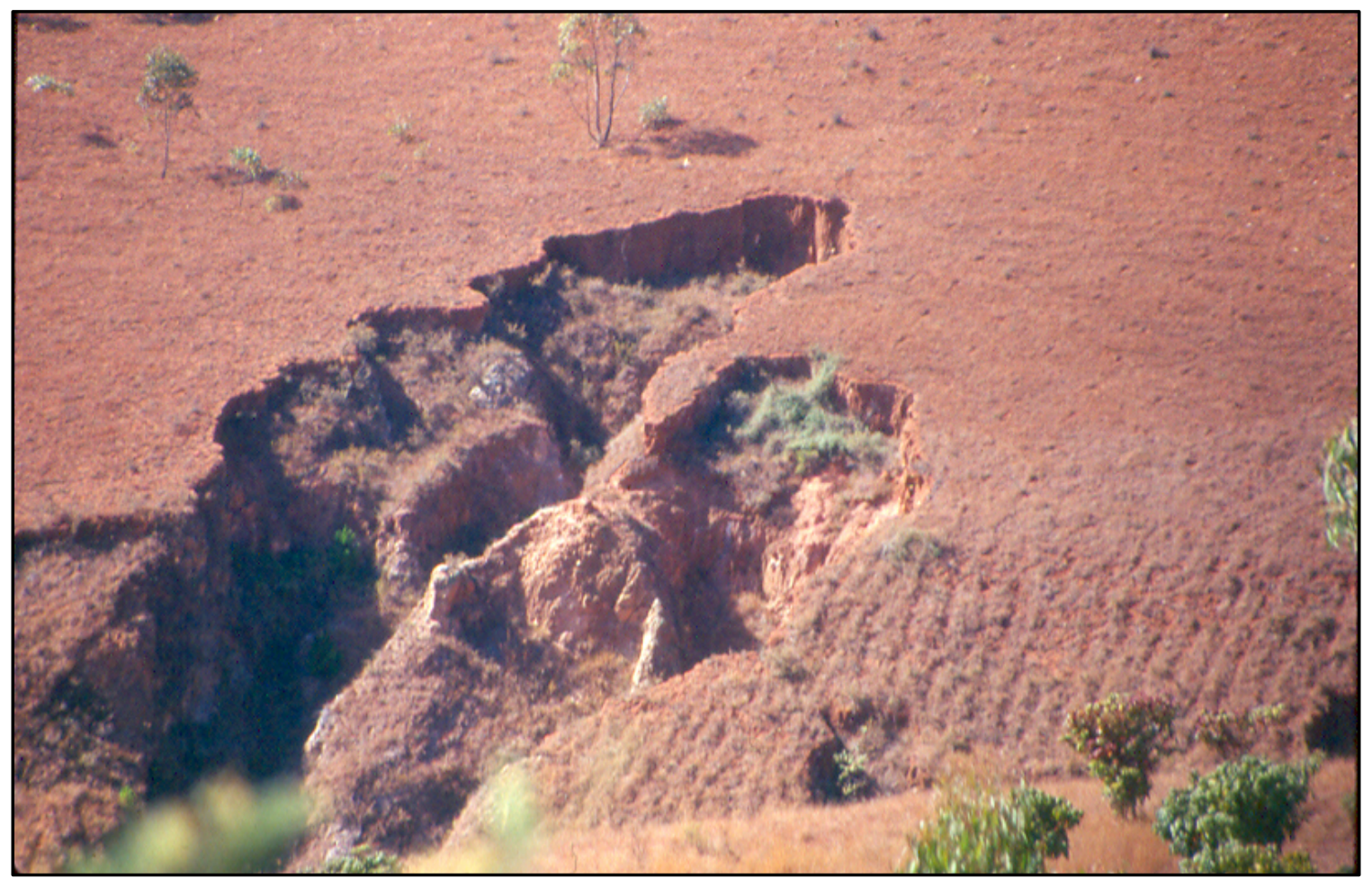


Figure 3c. Newly forming lavaka. Photo: J. Unruh

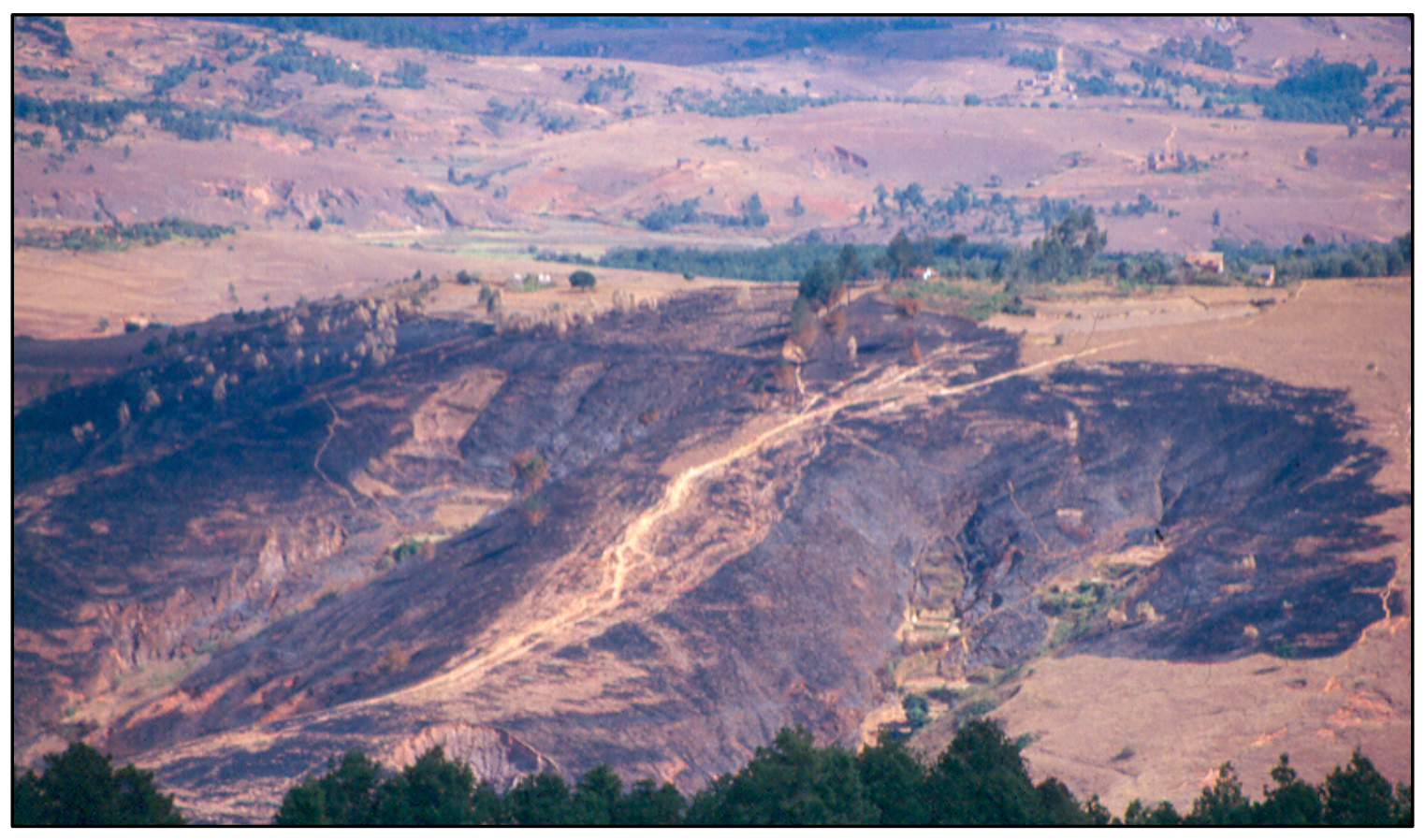

Figure 3d. Recently burned, older lavaka. Photo: J. Unruh 
Figure $4 \mathrm{a}-\mathrm{d}$

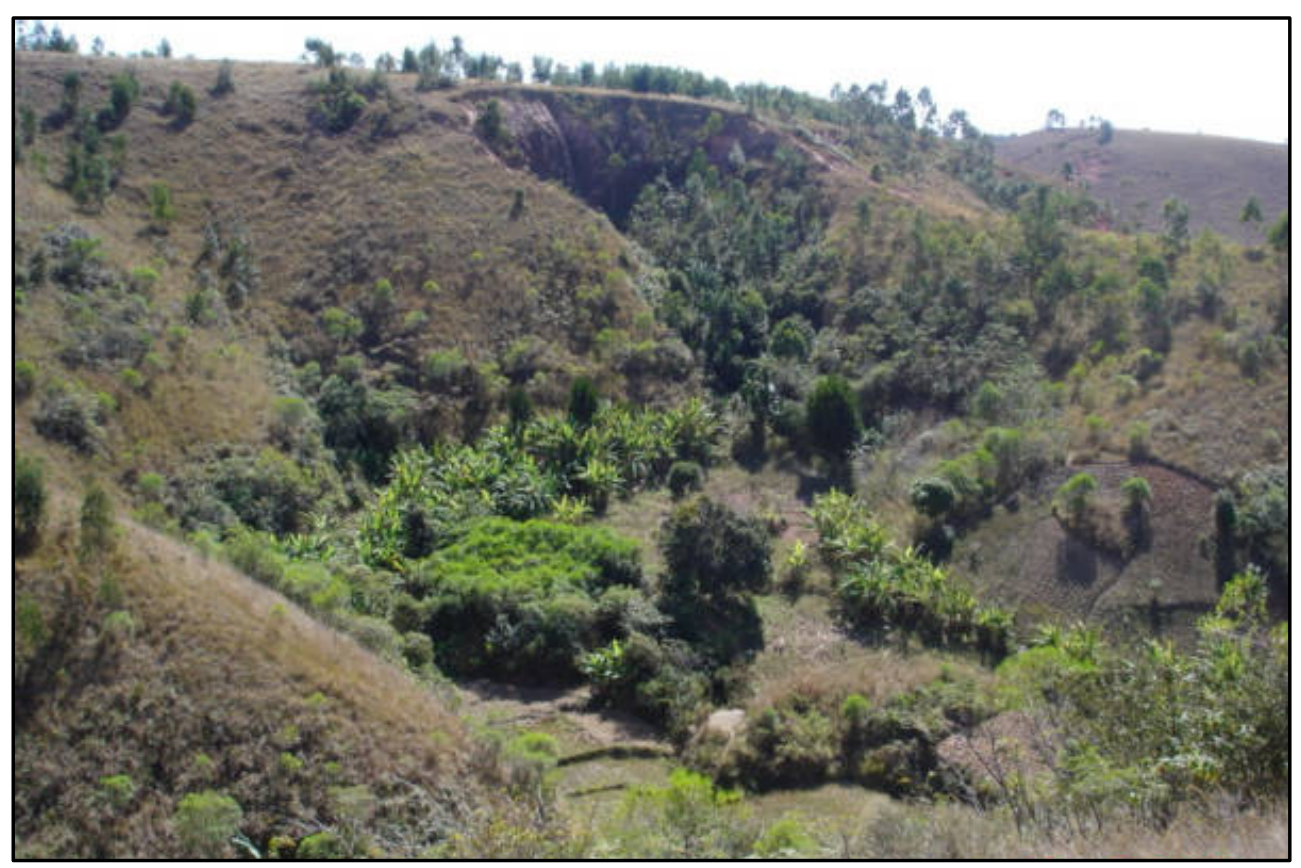

Figure 4a. Cultivation in outfall area of vegetated, lightly active lavaka. Photo: Team Lavaka Image Collection, Jungers $\mathrm{M}$. 


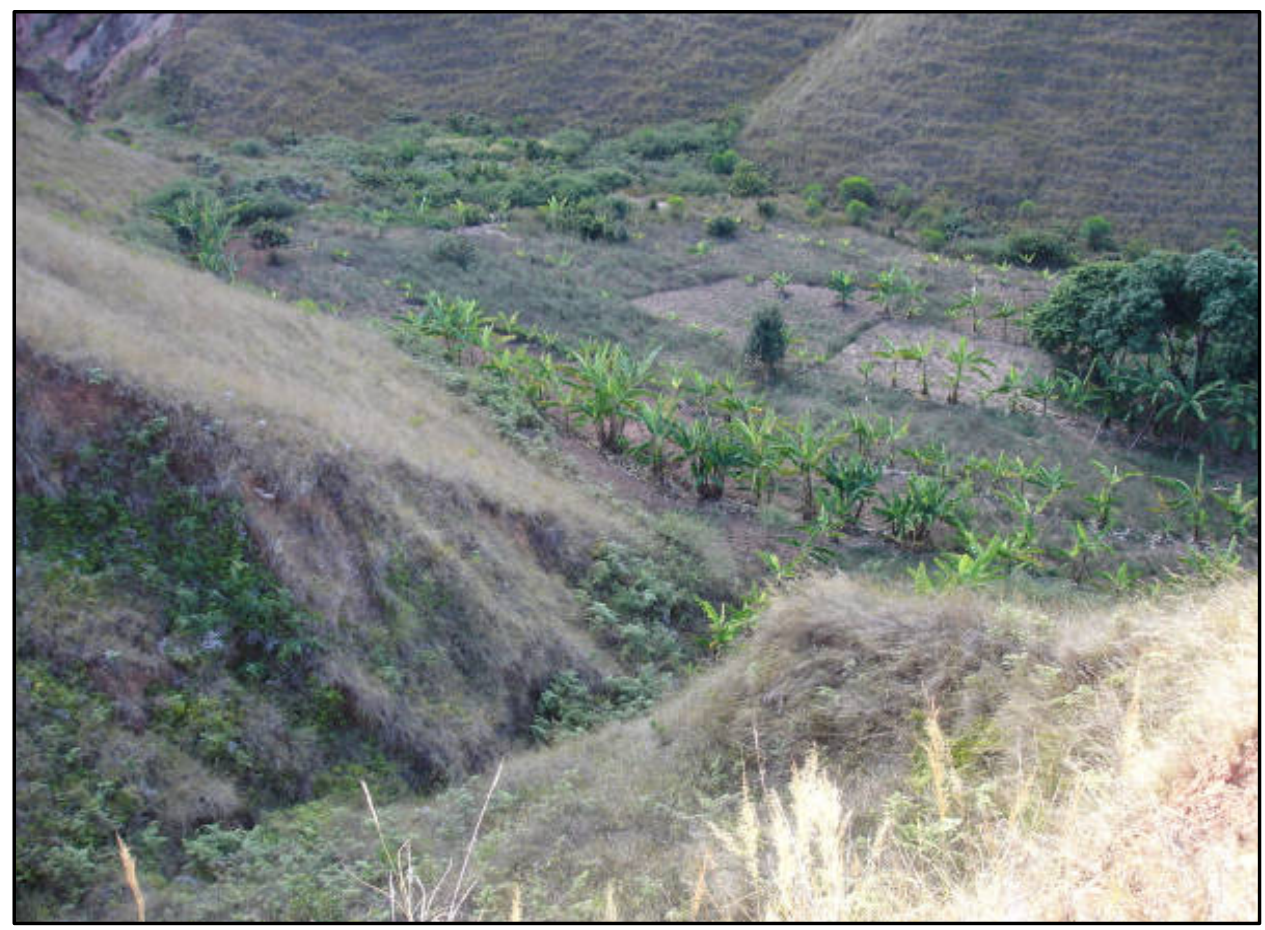

Figure $4 \mathrm{~b}$. Bananas and fields in outfall area of largely inactive, vegetated lavaka. Photo: Team Lavaka Image Collection, R Cox, 


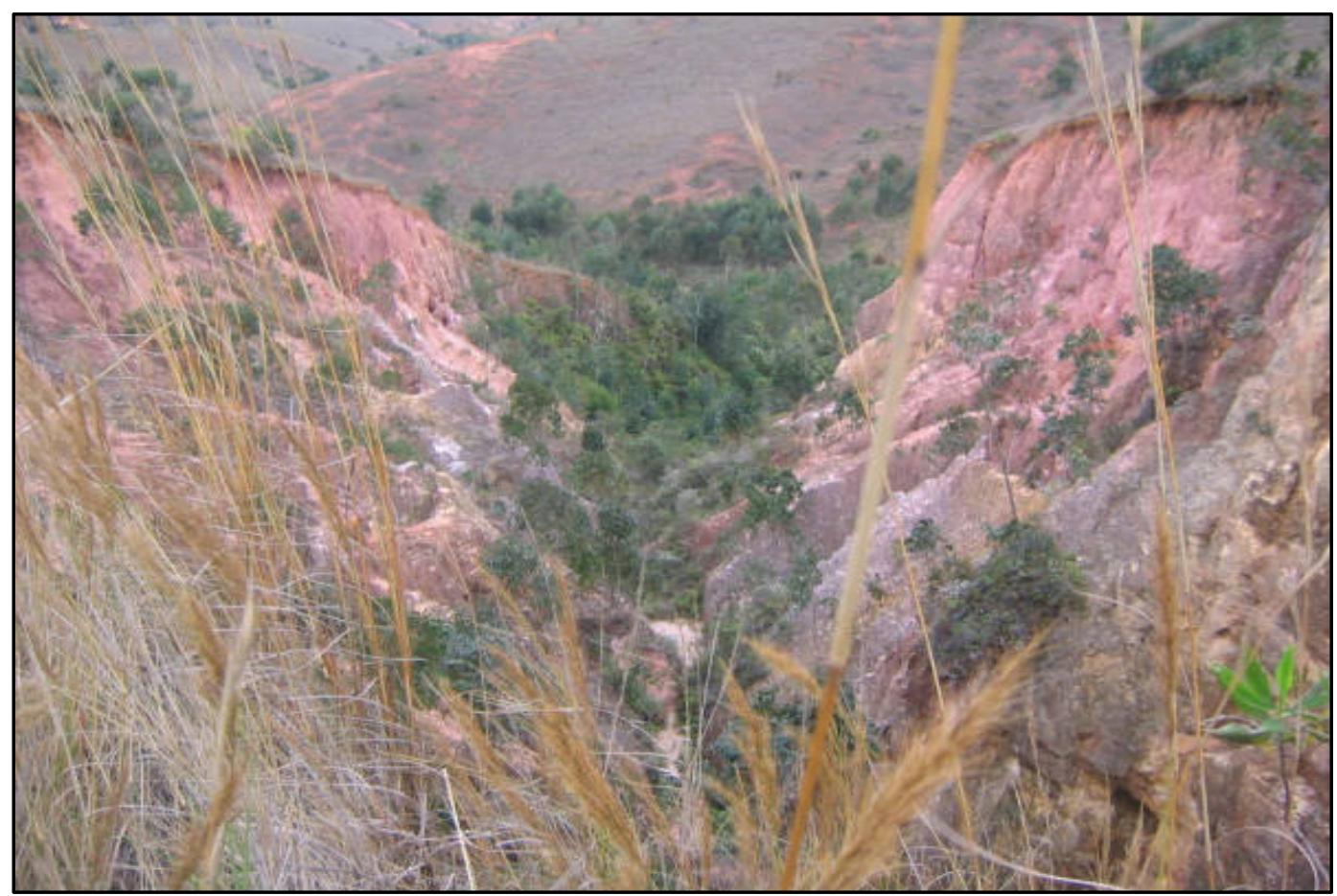

Figure 4c. Trees colonising active lavaka. Photo: Team Lavaka Image Collection, R. Cox.

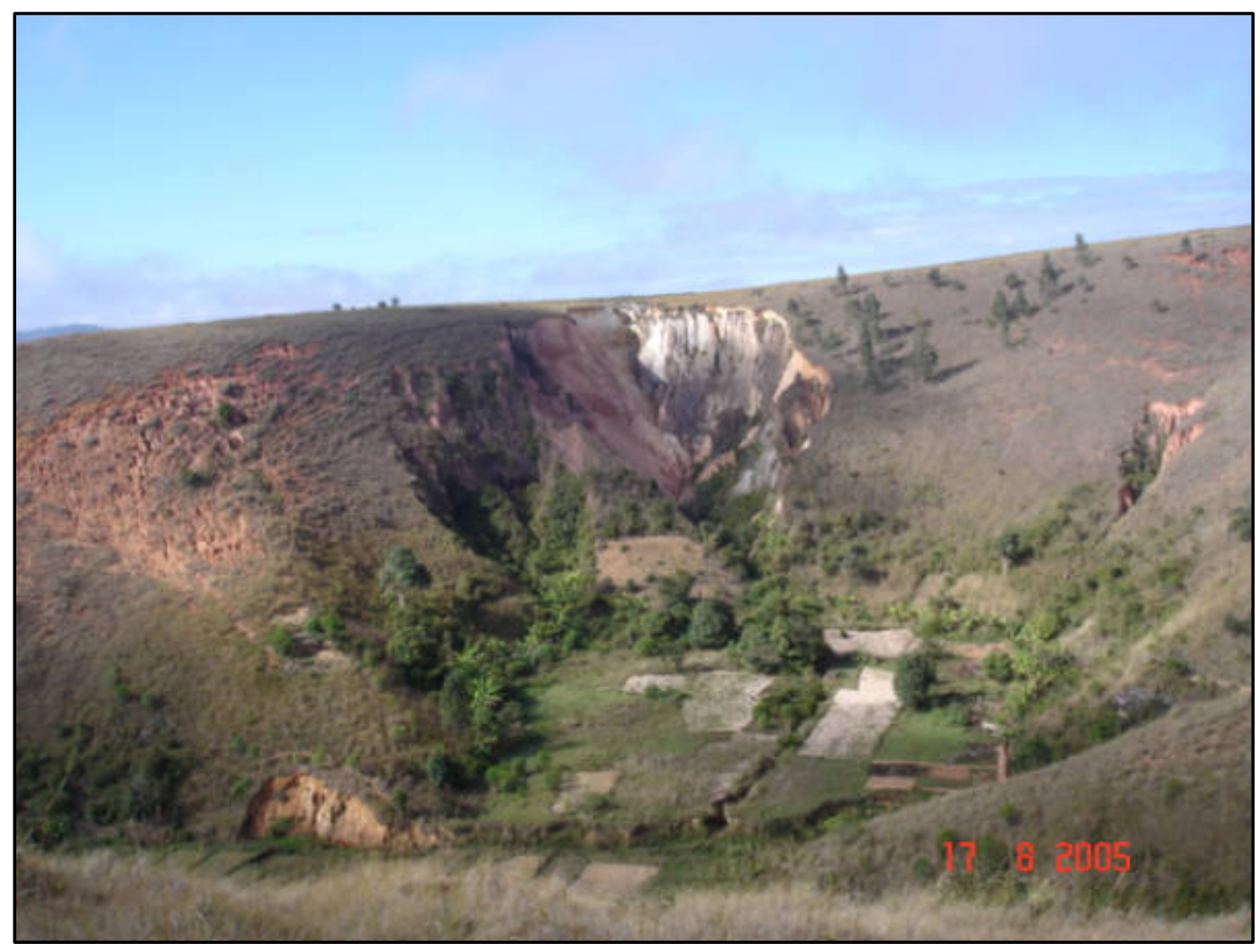

Figure 4d. Agriculturally occupied lavaka outflow. Photo: Team Lavaka Image Collection, M. Jungers 
Figure 5 a - c

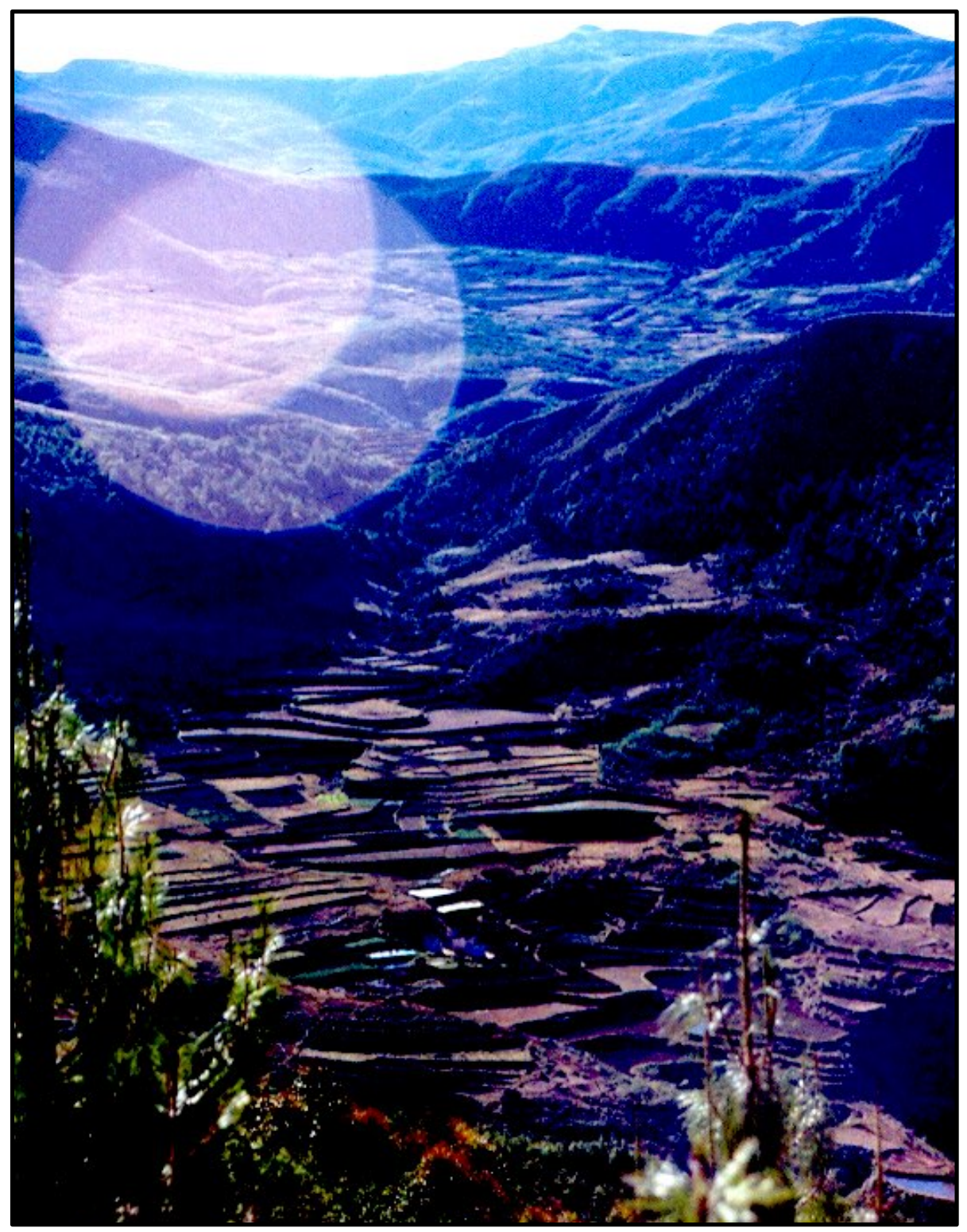

Figure 5a. Mature lavaka as a side valley with intensive agriculture. Photo: J. Unruh 


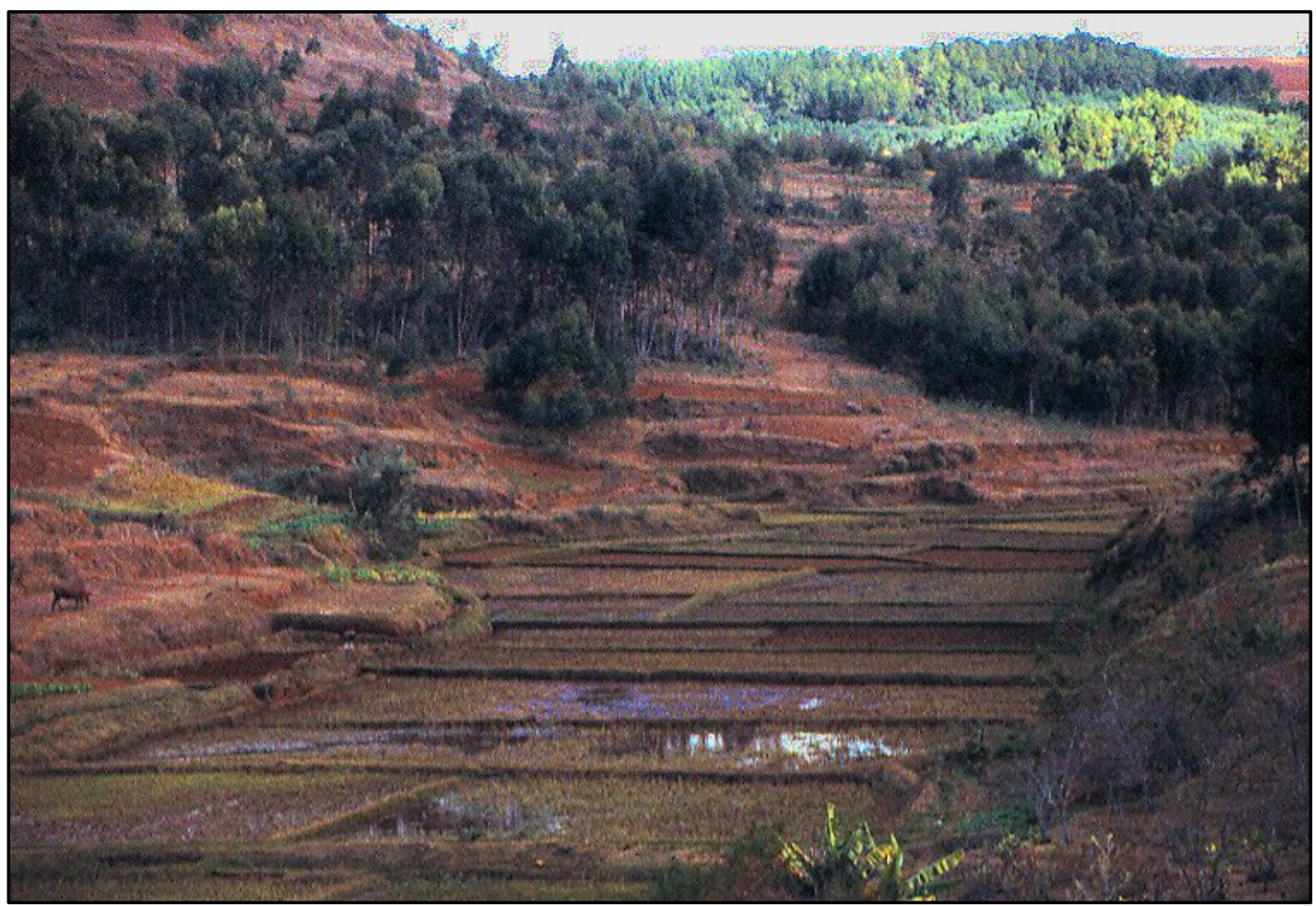

Figure 5b. Mature lavaka with crops and trees. Photo: J. Unruh

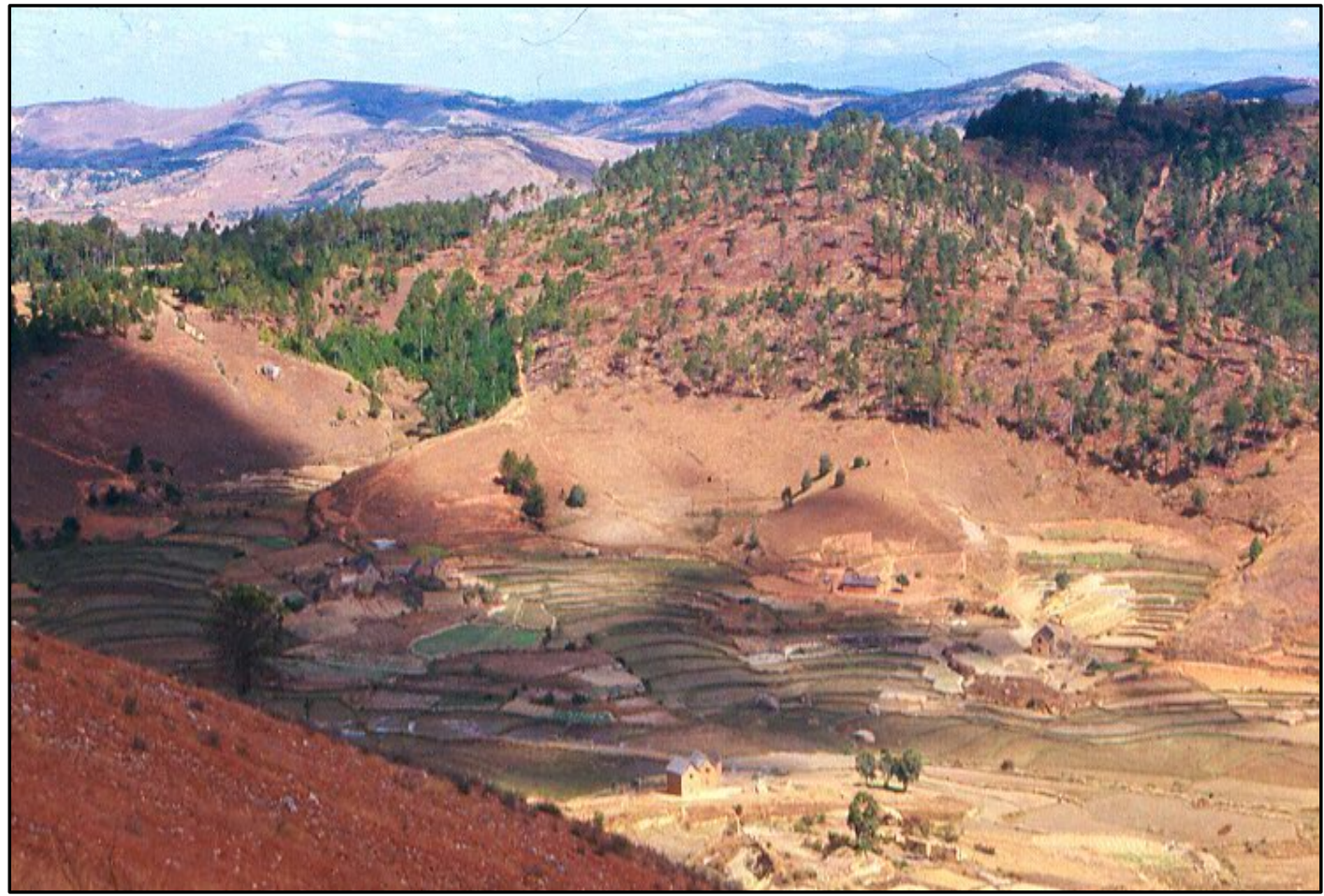

Figure 5c. Mature lavaka with terracing and homestead buildings (lower center). Photo: J.Unruh 
Figure 6 a - b

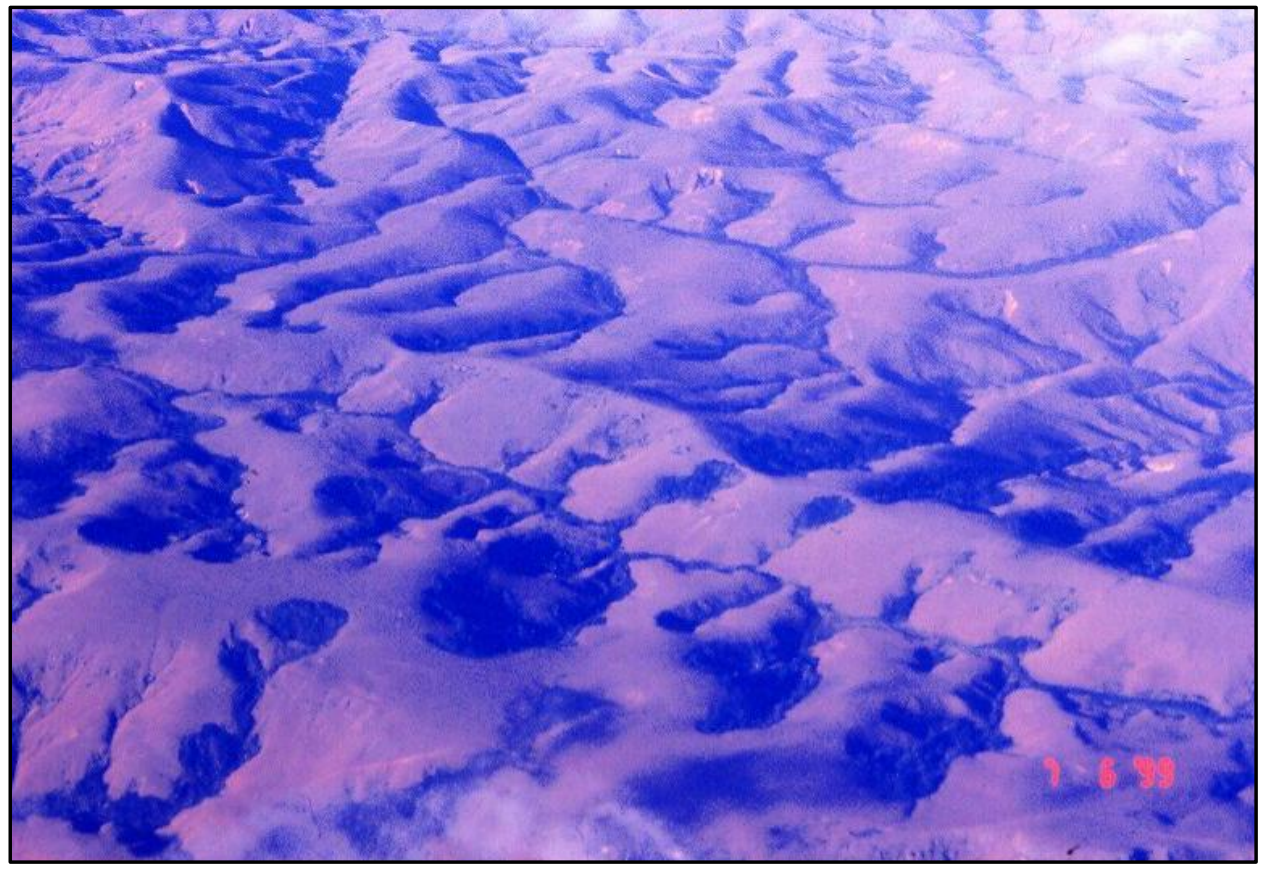

Figure 6a. Air photo of numerous lavaka. Photo: J. Unruh 


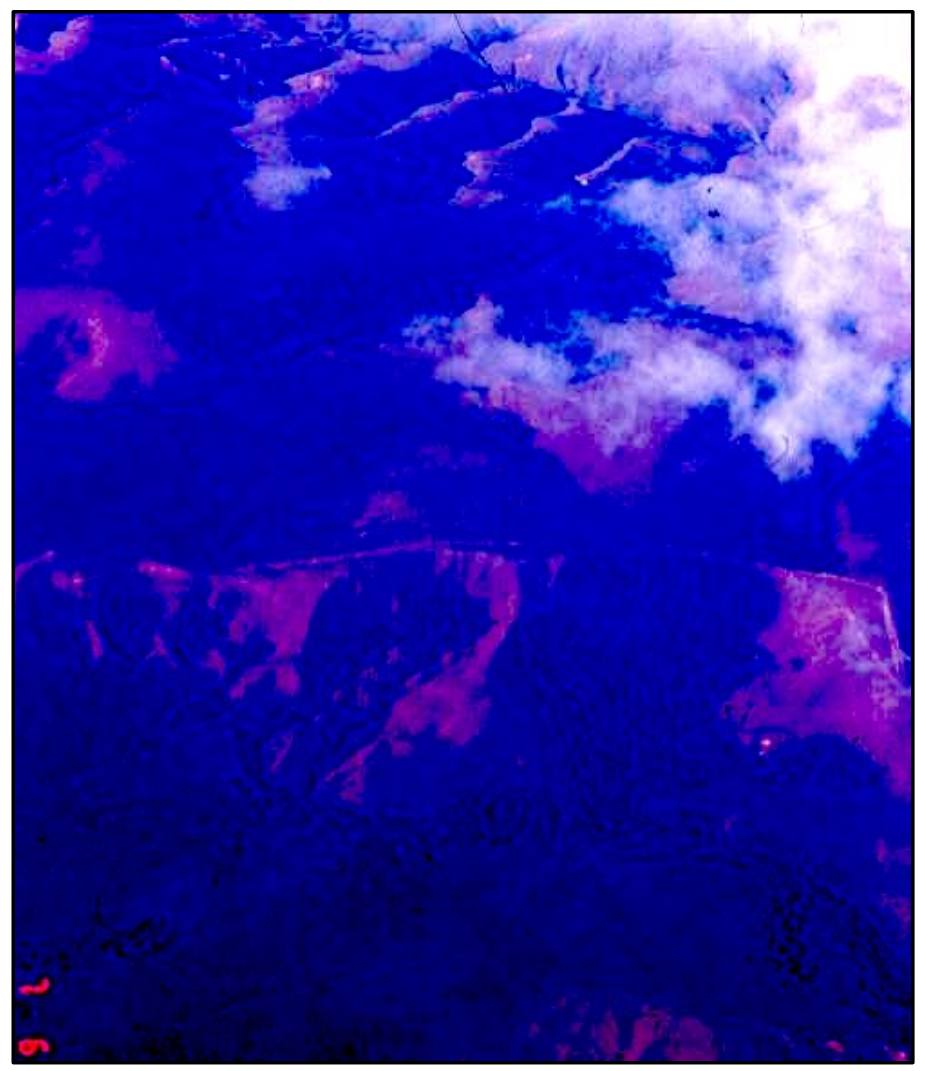

Figure 6 b. Lavaka colonized by tree regrowth. Photo:

J. Unruh 